\title{
Contravención electoral en la publicidad politica de los candidatos al Congreso de la República en Boyacá (Colombia), 2018
}

\section{Electoral contravention in the political advertising of the candidates to the Congress of the Republic in Boyacá (Colombia), 2018}

\section{Mario Alexander Lozano Garcia iD}

Universidad de Boyacá

malozano@uniboyaca.edu.co

\section{Olga Sofia Morcote González iD}

Universidad de Boyacá

olgmorcote@uniboyaca.edu.co

\section{Resumen}

El artículo desarrolla el contexto colombiano 'elecciones de Congreso de la República 2018', desde el comportamiento dado al manejo de la publicidad politica exterior por parte de algunos candidatos del departamento de Boyacá. Básicamente se exponen y analizan casos de contravención electoral al momento de emplear estrategias de visualización en los anuncios políticos. El texto surge del proyecto Comportamiento electoral en Boyacá 2018: desde las contiendas Congreso de la República y Presidencial, en el cual se indagó sobre el manejo de la propaganda política de los diversos aspirantes, se resaltaron las faltas más comunes, contempladas en los códigos Civil, Electoral, Tránsito y Transporte, y Nacional de Policía.

Palabras clave: Elecciones Congreso 2018-Colombia, departamento de Boyacá, candidatos al Congreso, estudio sobre contravención, sistema electoral.

\begin{abstract}
The article develops the Colombian context 'elections of the Congress of the Republic 2018', from the behavior given to the handling of foreign political advertising by some candidates from the department of Boyacá. Basically they are exposed and analyzed, cases of electoral contravention when employing visualization strategies in political announcements. The text emerges from the project Electoral behavior in Boyacá 2018: from the contests Congress of the Republic and Presidential, where it was investigated on the handling of the political propaganda of the various candidates, highlighting the most common faults, contemplated in the Civil, Electoral, Transit and Transportation, and National Police.
\end{abstract}

Keywords: Elections Congress 2018-Colombia, Boyacá Department, candidates for Congress, study on contravention, electoral system.

Artículo: Recibido el 28 de febrero de 2019 y aprobado el 14 de febrero de 2020. 


\section{Cómo citar este artículo:}

Lozano García, M. A. \& Morcote González, O.S. (2020). Contravención electoral en la publicidad política de los candidatos al Congreso de la República en Boyacá (Colombia), 2018. Reflexión Política 22(44), pp. 26-38. doi: 10.29375/01240781.3521

\section{Introducción}

"En voz de la propia ciudadanía, la publicidad politica de los partidos carece de interés y debido a su desmedida repetición durante las elecciones termina por hartar al público consumidor de medios sin importar su intención de voto o su identificación partidista"

(Juárez, 2010)

La literatura científica define el término contravención como la "infracción de disposiciones municipales o policiales" (Ossorio, 1981), "falta que se comete al no cumplir lo ordenado" (González, 2006, p. 257); mientras que desde el Derecho Administrativo se explica como los "ataques realizados a sectores del dominio público, cuyo conocimiento corresponde ya a los Tribunales Administrativos, y a las jurisdicciones represivas judiciales" (Enciclopedia jurídica, 2014); también, "aquel comportamiento humano que produce un daño social de menor entidad del delito y por eso se conmina con sanciones generalmente leves" (MINJUSTICIA, sf.) e "infracción, vulneración de una norma" (DEJ, 2018; MINJUSTICIA, sf.). Otros autores señalan que la comisión de una contravención constituye una perturbación a la convivencia social a la cual debe aplicarse una dogmática especial (Torres, 2008, p. 2). Como tales distinciones obedecen y coinciden en una conducta típica que conlleva a la infracción penal de un código, por razones voluntarias o en algunos casos hasta involuntarias, este último juicio hipotéticamente puede darse como cierto desconocimiento normativo que genera comportamientos antijurídicos enmarcados en la teoría del delito, definida como las "acciones u omisiones dolosas o culposas penadas por Ley", que obviamente ponen en riesgo la integridad social y afrenta la Constitución Política.

Tales apreciaciones conceptuales y teóricas permiten articular, para el caso colombiano, el contexto desarrollado en las elecciones de Congreso de la República 2018, desde el comportamiento dado al manejo de la publicidad política por parte de algunos candidatos del departamento de Boyacá quienes intervinieron como aspirantes al Senado o Cámara de Representantes. Exactamente se concretan algunos ejemplos de contravención electoral al momento de emplear estrategias de visualización de su imagen política, que termina siendo expuesta en el escenario público mediante el uso de la publicidad exterior como pasacalles, vallas, pendones, carteles, avisos en murales y demás soportes de refuerzo visual ubicados en sitios estratégicos de zonas urbanas y rurales.

Por su parte, la Ley 140 de 1994 señala que se entiende por Publicidad Exterior Visual, el medio masivo de comunicación destinado a informar o llamar la atención del público a través de elementos visuales como leyendas, inscripciones, dibujos, fotografias, signos o similares, visibles desde las vías de uso o dominio público, bien sean peatonales o vehiculares, terrestres, fluviales, marítimas o aéreas.

En tanto el artículo primero no considera Publicidad Exterior Visual

la señalización vial, la nomenclatura urbana o rural, la información sobre sitios históricos, turísticos y culturales y aquella información temporal de carácter educativo, cultural o deportivo que coloquen las autoridades u otras personas por encargo de éstas, que podrá incluir mensajes comerciales o de otra naturaleza siempre y cuando éstos no ocupen más del 30\% del tamaño del respectivo mensaje o aviso (Ley 140 de 1994, p. 1). 
De manera que, el objeto de la Ley 140 de 1994 es

mejorar la calidad de vida de los habitantes del país, mediante la descontaminación visual y del paisaje, la protección del espacio público y de la integridad del medio ambiente, la seguridad vial y la simplificación de la actuación administrativa en relación con la Publicidad Exterior Visual (1994, p. 1).

Establece en el artículo tercero los lugares del territorio nacional en donde no puede ubicarse publicidad exterior:

- En las áreas que constituyen espacio público de conformidad con las normas municipales, distritales y de las entidades territoriales indígenas que se expidan con fundamento en la Ley $9^{\circ}$ de 1989 o de las normas que la modifiquen o sustituyan. Sin embargo, podrá colocarse Publicidad Exterior Visual en los recintos destinados a la presentación de espectáculos públicos, en los paraderos de los vehículos de transporte público y demás elementos de amoblamiento urbano, en las condiciones que determinen las autoridades que ejerzan el control y la vigilancia de estas actividades.

- Dentro de los 200 metros de distancia de los bienes declarados monumentos nacionales.

- Donde lo prohíban los Concejos Municipales y Distritales conforme a los numerales $7^{\circ}$ y $9^{\circ} \mathrm{del}$ artículo 313 de la Constitución Nacional.

- En la propiedad privada sin el consentimiento del propietario o poseedor.

- Sobre la infraestructura, tales como postes de apoyo a las redes eléctricas y telefónicas, puentes, torres eléctricas y cualquier otra estructura de propiedad del Estado (Ley 140 de 1994).

Además, el numeral cuarto de la norma señala las condiciones de la Publicidad Exterior Visual en zonas urbanas y rurales como:

- Distancia: podrán colocarse hasta dos vallas contiguas con la Publicidad Exterior Visual. La distancia mínima con las más próximas no puede ser inferior a 80 metros. Dentro de los dos (2) kilómetros de carretera siguiente al límite urbano y territorios indígenas podrá colocarse una valla cada 200 metros, después de este kilometraje se podrá colocar una valla cada 250 metros.
- Distancia de la vía: la Publicidad Exterior Visual en las zonas rurales deberá estar a una distancia mínima de quince metros lineales (15 mts/L) a partir del borde de la calzada. La ubicación de la Publicidad Exterior Visual en las zonas urbanas la regularán los Concejos Municipales.

- Dimensiones: se podrá colocar Publicidad Exterior Visual en terrazas, cubiertas y culatas de inmuebles construidos, siempre y cuando su tamaño no supere los costados laterales de dichos inmuebles.

- La dimensión de la Publicidad Exterior Visual en lotes sin construir no podrá ser superior a cuarenta y ocho metros cuadrados (48 mts2).

Precisamente, las anteriores faltas terminan siendo notorias en el manejo dado a la publicidad política empleada por algunos candidatos boyacenses en sus campañas a las elecciones legislativas, donde se evidencian avisos ubicados en propiedades privadas sin consentimiento del propietario, carteles fijados en infraestructura de propiedad del Estado como postes de alumbrado eléctrico, redes telefónicas, puentes, más de tres vallas contiguas separadas con menos de 80 metros. Asimismo, la ubicación de vallas con distancia mínima de dos metros lineales a la vía carreteable tipo autopista, principal, secundaria y hasta férrea.

Por otra parte, las llamadas 'correrías electorales' empleadas en las vías boyacenses a través de vehículos automotores muestran otro tipo de contravención relacionado con la violación al Código de Tránsito y Transporte. Por ejemplo, la circulación de motociclistas irrespetando o faltando a las normas generales establecidas en el Código, la negativa de usar el cinturón de seguridad o el transporte de pasajeros en el platón de camionetas tipo Pick Up, esta última infracción es una práctica común que presentaron las caravanas de vehículos a favor de las candidaturas, especialmente durante los últimos días de campaña donde habitualmente se concentran y desfilan por las principales calles de las municipalidades grandes grupos de seguidores.

Los términos de publicidad política $\mathrm{y}$ propaganda electoral son relacionados por la Misión de Observación Electoral-MOE como

la lógica que rige el desarrollo de una campaña electoral es el mecanismo por medio del cual los ciudadanos que aspiran a ocupar un cargo de elección popular se dan a conocer y motivan a 
los votantes para que apoyen a sus aspiraciones, ideas y proyectos. (MOE, 2015, p. 5).

En tanto propaganda electoral reside en la divulgación política es la que con carácter institucional realicen los partidos, movimientos, con el fin de difundir y promover los principios, programas y realizaciones de los partidos y movimientos, así como sus políticas frente a los diversos asuntos de interés nacional. (Artículo 23 de la Ley 130 de 1994).

Sin embargo, ambas definiciones aparentemente son similares, pero en la práctica resultan contrarias en razón a valorar en la 'publicidad política' como algo de todos, lo visible, lo que termina siendo debatido por todas las esferas de la sociedad; mientras que la 'divulgación política', lleva una relación directa con los hechos públicos que hacen parte de las instituciones, es decir el modo de presentar alguna propuesta gubernamental, corrientes ideológicas, y demás líneas de acción a favor de las comunidades.

El estudio actual surge del proyecto Comportamiento electoral en Boyacá 2018: desde las contiendas Congreso de la República y Presidencial, investigación que dentro de sus objetivos está indagar acerca del manejo de la publicidad exterior alusiva a las candidaturas de aspirantes al Congreso. Para ello, se toma como unidad de análisis principal el término contravención electoral en la publicidad política, resaltando las faltas más comunes que generó el empleo de publicidad exterior. Asimismo, se indaga sobre otros tipos de violación al Código de Tránsito y Transporte que es formulado mediante la Ley 769 de 2002. Estas infracciones son catalogadas por la Ley 1153 de 2007 como "pequeñas causas en materia penal", debido a conductas de acción y omisión que describe la misma norma en el artículo $3^{\circ}$. Igualmente, en la Ley 140 de 1994 se reglamenta la "Publicidad exterior Visual en el territorio nacional", la cual termina siendo vulnerada por algunos candidatos que, al parecer, desconocen los principales apartados, como la prohibición de publicidad exterior, "sobre infraestructuras de propiedad del Estado” (Ley 140 de 1994).

De manera que, con el objetivo general a desarrollar, se permitirá exponer algunas violaciones consagradas en los códigos Electoral, Tránsito y Transporte, y Penal, durante el debate legislativo 2018 en el departamento de Boyacá. Asimismo, se examina la intervención de las autoridades locales (caso Alcaldía de Tunja), al publicar el Decreto Municipal 0384 del 31 de diciembre de 2017 donde se amparan los principales principios rectores que componen de forma sistemática la legislación nacional sobre el tema 'publicidad electoral'.

Las anteriores líneas merecen ser valoradas en el siguiente trabajo, no con el fin de describir solamente las faltas a los códigos y leyes mencionadas, o realizar alguna denuncia contra las candidaturas que resultan del diario vivir en los procesos electorales de Colombia y son prácticas comunes sujetas a un estilo propio de la cultura electoral del país. Se busca presentar desde el ámbito académico e investigativo faltas comunes o menores que ocurren en las correrías políticas; estas representan algún deterioro a los bienes públicos, irrespeto al mobiliario urbano o viviendas particulares; a su vez, afectación a la salud pública, tomada desde los altos niveles de ruido que provocan concentraciones masivas de seguidores en plazas municipales, la utilización de potentes amplificadores que sobrepasan los decibeles de sonido, y el empleo de sirenas o cornetas que hacen su presencia sonora durante los desfiles de automotores en los cierres de campaña.

Juan Manuel Grijalvo (2000) califica tales acciones como "impacto visual", y las define con una acepción descalificativa o, como una agresión que padece nuestra vista, un golpe a nuestro sentido estético, "fa mal d'ulls"; en lo acústico hay un impacto ecológico o ambiental. La Constitución política de 1991, intenta mitigar este tipo de faltas a través del artículo 79 ,

Todas las personas tienen derecho a gozar de un ambiente sano. La ley garantizará la participación de la comunidad en las decisiones que puedan afectarlo. Es deber del Estado proteger la diversidad e integridad del ambiente, conservar las áreas de especial importancia ecológica y fomentar la educación para el logro de estos fines. (Const., 1991)

Estos planteamientos llevan a formular la pregunta central: ¿Cuál fue el comportamiento de los candidatos de Boyacá al Congreso de la Republica 2018, frente a las contravenciones electorales en materia de publicidad política? A su vez, esta cuestión se dilucida mediante las siguientes sub-preguntas:

P1: ¿Cómo se manifestó la contravención electoral en las actuaciones de candidatos al Congreso 2018 en el departamento de 


\section{Boyacá?}

P2: ¿De qué manera se muestran las faltas más comunes en materia de publicidad política que cometieron los candidatos al Legislativo por Boyacá-2018?

P3: ¿Qué acciones llevó a cabo la Alcaldía de Tunja para evitar una posible omisión de las normas electorales en lo pertinente a la publicidad política exterior?

\section{Método}

La metodología utilizada en el presente estudio partió de la recolección de datos 'naturales', mediante una observación científica directa de tipo cualitativo que llevó al registro de insumos derivados de la propaganda política exterior ubicada en vías urbanas y rurales del departamento. Esta observación fue apoyada por un registro fotográfico que evidencia las irregularidades más comunes en el manejo o empleo de estrategias promocionales visuales que desarrollaron los candidatos a la Cámara de Representantes y Senado. Esta metodología es definida como "la inspección y estudio realizado por el investigador, mediante el empleo de sus propios sentidos, con o sin ayuda de aparatos técnicos, de las cosas o hechos de interés social, tal como son o tienen lugar espontáneamente" (Sierra Bravo, 1998).

Es decir, mediante la observación se logró inspeccionar directamente las contravenciones electorales en el periodo comprendido entre el 11 de diciembre de 2017 y el 11 de marzo de 2018, época para hacer proselitismo político según el Consejo Nacional Electoral-CNE, órgano estatal encargado de velar por la transparencia y eficacia en los procesos de elección popular en Colombia, de conformidad con el artículo 256 de la Constitución Política. En ese tiempo fueron tomadas y analizadas 342 fotografias de infracciones, de estas se seleccionaron solo 15 por razones de espacio para el siguiente trabajo, las cuales demuestran algunos desacatos normativos.

Las zonas urbanas y rurales indagadas hacen parte de los municipios Tunja (CapitalDepartamento de Boyacá), Chivata, Toca, Combita, Arcabuco, Moniquirá, Cucaita, Villa de Leyva, Samacá, Chiquinquirá, Santa Sofia, Sutamarchán, entre otros. Una vez tomadas las 15 imágenes se procedió a construir la tabla Contravenciones electorales - publicidad exterior candidatos al Congreso por Boyacá 2018, sitio de registro visual que parte de tres ejes principales: sustento legal (Artículo), la descripción fotográfica (imagen), Contravención (conforme a los códigos Electoral, Tránsito y Transporte, $\mathrm{y}$ Penal). Esto busca organizar la información pesquisada y demostrar su veracidad en cuanto a la trasgresión legal.

\subsection{Discusión de la tabla: Contravenciones electorales - publicidad exterior candidatos al Congreso por Boyacá 2018}

Los principales hallazgos (tabla 1.) evidencian infracciones reiterativas a las leyes 140 de 1994 y 769 de 2002, especialmente en el manejo de la publicidad exterior y violación al Código de Tránsito y Transporte, desacatos comunes durante las elecciones legislativas 2018 en el departamento de Boyacá. Estos hechos terminan siendo visualizados mediante la ubicación de vallas publicitarias de forma irregular, carteles o afiches fijados en infraestructura de propiedad del Estado, vallas en plena vía férrea, caravanas vehiculares de seguidores de candidatos faltando al uso del cinturón de seguridad o automotores transportando pasajeros en el platón de camionetas tipo Pick Up.

Dichas infracciones son consideradas en el derecho como violaciones menores o bagatela, Román (2015), citado por Juan Carlos Forero (2006), sugiere que esta expresión tuvo su origen

en la Europa de la posguerra cuando, en virtud de las circunstancias socioeconómicas se produce un evidente incremento de los delitos contra el patrimonio económico, una de cuyas características básicas era la de su pequeña relevancia y la frecuencia en su comisión (Forero, 2006, p. 245).

La bagatela es definida por el diccionario de la Real Academia Española como "cosa de poca importancia o valor”, dicho vocablo termina siendo esgrimido contra la infraestructura civil del Estado y viola algunos artículos estipulados en el Código de Tránsito Terrestre.

Estas faltas también terminan siendo contempladas en el Código Nacional de Policía, en cuanto a "comportamientos que afectan la integridad urbanística", como lo consagra el Artículo 135, "comportamientos contrarios al cuidado e integridad del espacio público", numeral 140; precisamente, este último destaca los ítems:

- Ensuciar, dañar o hacer un uso indebido o abusivo de los bienes fiscales o de I uso 
público o contrariar los reglamentos o manuales pertinentes.

- Escribir o fijar en lugar público o abierto al público, postes, fachadas, y antejardines, muros, paredes, elementos físicos naturales, tales como piedras y troncos de árbol, de propiedades públicas o privadas, leyendas, dibujos, graffitis, sin el debido permiso, cuando éste se requiera o incumpliendo la normatividad vigente.

- Fijar en espacio público propaganda, avisos o pasacalles, pancartas, pendones, vallas o banderolas, sin el debido permiso o incumpliendo las condiciones establecidas en la normatividad vigente. (Ley 1801, 2016, p. 80)

Infracciones menores que versan contra el espacio público (contaminación visual y/o auditiva) $\mathrm{y}$, a su vez, atentan contra la integridad civil al hacer uso inadecuado de bienes físicos como postes de alumbrados eléctricos o redes telefónicas, puentes peatonales, barreras viales de seguridad que fueron empleadas en las diversas campañas electorales como fijación de carteles informativos improvisados de los mismos aspirantes, lo que desconoce ciertos riesgos para las comunidades que encuentran modos de uso improcedentes en la infraestructura del Estado, ejemplo de ello son los muros o barreras de contención instalados en los márgenes centrales de la vía de circulación, los cuales fueron adornados con avisos y afiches de candidatos, lo que omite las características primordiales que ofrece "barreras de seguridad para el impacto automotor en zonas de alta accidentalidad, recubierta con pintura termoplástica”, según concepto técnico del Grupo TDM, especializado en desarrollar obras viales.

A su vez, el Código Nacional de Policía establece el derecho de reunión, destacando en el Artículo $47^{\circ}$ las formas de "aglomeración de público toda reunión de un número plural de personas producto de una convocatoria individual o colectiva" (Ley 1801, 2016, p. 23), tal aglomeración establece las siguientes categorías:

- Reuniones o manifestaciones públicas y pacíficas en el espacio público.

- Actividades que involucran aglomeraciones de público no complejas.

- $\quad$ Actividades que involucran aglomeraciones de público complejas (Ley 1801, 2016, p. 23).
Esto fue visible en los encuentros en plazas públicas o manifestaciones en las principales vías urbanas, donde se presentaron contravenciones al Código de Policía, al notarse infracciones viales (no usar el cinturón de seguridad, circular en sentido contrario $u$ omitir señales de tránsito), hicieron parte de las faltas electorales menores durante las contiendas legislativas en Boyacá. De igual forma, la violación al Artículo 49 "Consumo controlado de bebidas alcohólicas en lugares habilitados para aglomeraciones. En los lugares habilitados para aglomeraciones" (Ley 1801, 2016, p. 24), faltas repetitivas en las concentraciones políticas promovidas por los aspirantes boyacenses, siendo notorio en varios municipios, en donde se incurrió en el expendio de bebidas alcohólicas en lugares prohibidos, consumo en menores de edad, uso de alcohol durante las caravanas de automotores (véase desacatos a la Ley 769 de 2002: artículos 2 y 83), e infracción al decreto de 'Ley seca', el cual restringe la venta de licor y dispendio de tales bebidas, conforme al horario dispuesto por las autoridades ejecutivas.

Otras faltas percibidas en el periodo electoral que atentan contra el Código Nacional de Policía fueron el quebrantamiento al Artículo $29^{\circ}$ "Autorización de actos o eventos que involucren el uso y aprovechamiento de artículos pirotécnicos"; y las faltas permanentes al Artículo $33^{\circ}$ "Comportamientos que afectan la tranquilidad y relaciones respetuosas de las personas", esencialmente en lo pertinente a la contaminación sonora, la cual perturbó la tranquilidad y orden público de las comunidades urbanas y rurales, en razón a efectuarse fiestas con altos decibeles de sonido, reuniones en establecimientos públicos o privados y perifoneo publicitario ilegal.

$\mathrm{Al}$ respecto, Claudio Rolle (2009) citado por Valdez, Huerta y Aguilar (2011) destaca que,

durante las campañas electorales, es común que las contendientes utilicen melodías, estribillos y canciones políticas o algún tipo de retórica musical como estrategia de persuasión, ya sea como parte de los spots propagandísticos de los candidatos y partidos; o en forma de ritmos o composiciones creadas ex profeso con el fin de llamar la atención, agradar, entretener, trasmitir un mensaje político y/o lograr persuadir a los electores. De hecho, el uso de la música, como instrumento de campaña, es una práctica común que se ha generalizado a nivel mundial, de tal forma que prácticamente 
Tabla 1. Contravenciones electorales - publicidad exterior candidatos al Congreso por Boyacá 2018.

\begin{tabular}{cl}
$\begin{array}{c}\text { Sustento } \\
\text { legal }\end{array}$ & \multicolumn{1}{c}{ Descripción } \\
\hline Ley & \multicolumn{1}{c}{ Artículo } \\
\hline & \\
& $\begin{array}{l}\text { Artículo 3․ Lugares de } \\
\text { ubicación. Podrá colocarse } \\
\text { Publicidad Exterior Visual } \\
\text { en todos los lugares del } \\
\text { territorio nacional, salvo } \\
\text { en los siguientes: }\end{array}$ \\
Ley 140 & $\begin{array}{l}\text { Inciso: E) Sobre la } \\
\text { infraestructura, tales como } \\
\text { postes de apoyo a las redes } \\
\text { (junio 23) }\end{array}$ \\
& $\begin{array}{l}\text { eléctricas y telefónicas, } \\
\text { puentes, torres eléctricas y } \\
\text { cualquier otra estructura } \\
\text { de propiedad del Estado. }\end{array}$
\end{tabular}

Contravención

Uso de

infraestructura eléctrica (poste de alumbrado), ubicado en el municipio de Tunja; afiche promocional candidato al Senado.

Foto

\section{Contravención}

Códigos/

Artículos

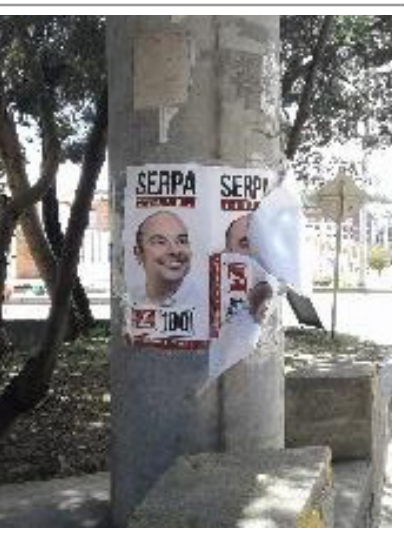

Código Civil

(Artículo XX)

y Código Electoral

colombiano

(Artículo 29)
Ley 140

de 1994

(junio 23)
Artículo $3^{\circ}$. Inciso: E.
Poste de red telefónica en zona veredal del municipio Toca; fijación de afiche candidato a la Cámara de Representantes.

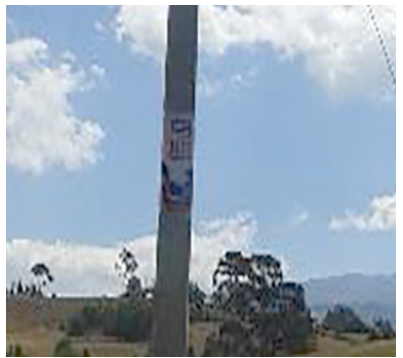

Código Civil

(Artículo XX)

y Código Electoral

(Artículo 29)
Ley 140

de 1994

(junio 23)
Artículo $3^{\circ}$. Inciso: E. o seguridad entre la vía Tunja - Arcabuco; fue pintado con publicidad de varios candidatos.

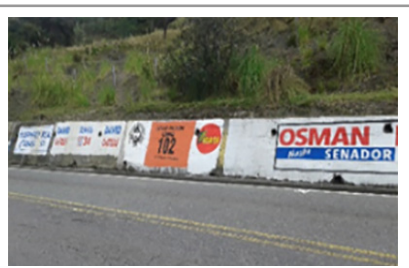

Código Civil

(Artículo XX), Código Electoral

(Artículo 29)

y Código de Tránsito

(Artículo XX)
Ley 140

de 1994

(junio 23)

Artículo $3^{\circ}$. Inciso: E.
Vía entre Tunja - Moniquirá, empleo de barreras de seguridad; publicidad pintada de aspirantes.
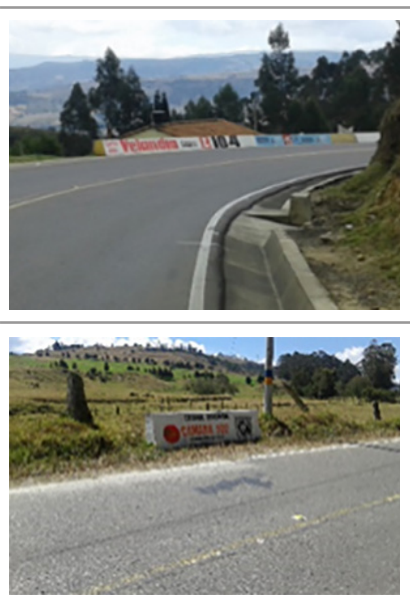

Carretera que une los municipios de

Ley 140 de 1994 (junio 23)

Artículo $3^{\circ}$. Inciso: E. Toca y Chivata; muro de seguridad, fijación de candidato a la Cámara de Representantes.
Código Civil

(Artículo XX), Código Electoral (Artículo 29) y Código de Tránsito (Artículo XX)
Código Civil

(Artículo XX), Código Electoral

(Artículo 29)

y Código de Tránsito

(Artículo XX)
Ley 140 de 1994 (junio 23)
Desvió hacía Samacá, vía entre Tunja y Villa de Leyva; muro de señalización pintado por aspirante al legislativo.

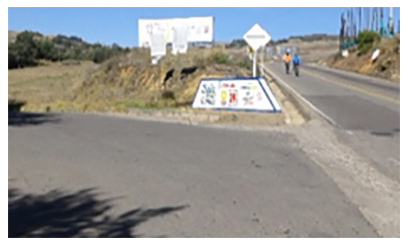

Código Civil

(Artículo XX), Código Electoral (Artículo 29) y Código de Tránsito (Artículo XX) 
Artículo 3․ Inciso: A) En las áreas que constituyen espacio público de conformidad con las

Ley $140 \mathrm{de}$ 1994 (junio 23) normas municipales, distritales y de las entidades territoriales indígenas que se expidan con fundamento en la Ley $9^{\circ}$ de 1989 o de las normas que la modifiquen o sustituyan [...].
Puente peatonal ubicado en la Universidad Pedagógica y Tecnológica de Colombia-UPTC, sede Tunja; afiches de candidatos al Congreso.

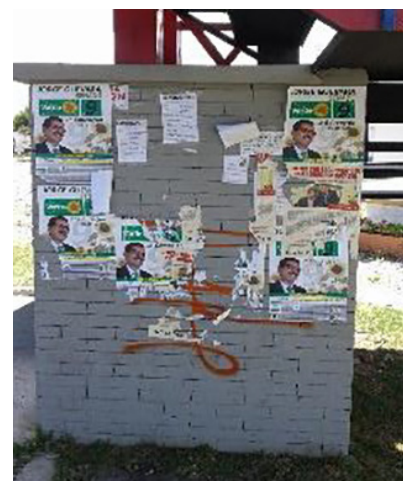

Código Electoral (Artículo 29

Propaganda en espacios públicos)
Ley $140 \mathrm{de}$ 1994 (junio 23)
Artículo $4^{\circ}$. Condiciones de la Publicidad Exterior Visual en zonas urbanas y rurales. La Publicidad Exterior Visual que se coloque en las áreas urbanas de los municipios, distritos y también en los territorios indígenas, deberá reunir los siguientes requerimientos:

B) Distancia de la vía: La Publicidad Exterior Visual en las zonas rurales deberán estar a una distancia mínima de quince metros lineales (15 mts/L) a partir del borde de la calzada[...]

Ley $140 \mathrm{de}$ 1994 (junio 23)

Artículo $4^{\circ}$. Inciso: B. mínima en relación con

Ley $140 \mathrm{de}$ 1994

el cruce de ferrocarriles, puentes, retenes y curvas pronunciadas será de doscientos cincuenta (250) metros.
Avenida de los Estudiantes, valla de aspirante, sobre la vía principal y en zona peatonal o cebras de cruce.

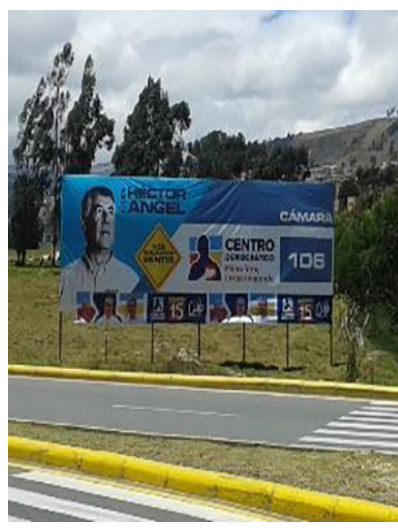

Código Electoral (Artículo 29) y Código de Tránsito (Artículo XX)
Valla de candidato a la Cámara de Representantes cerca a la vía urbana Avenida de los Estudiantes-Tunja.

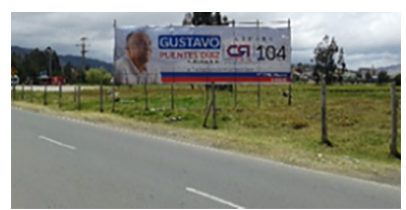

Código Electoral (Artículo 29) y Código de Tránsito (Artículo XX)
Vallas ubicadas al lado de la vía férrea que comunica los municipios de Tunja y Sogamoso, zona de paso por Tuta.

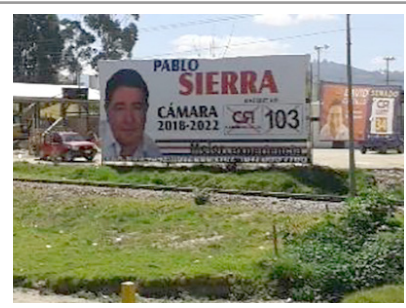

Código Electoral

(Artículo 29)

y Código de Tránsito

(Artículo XX)
Artículo $3^{\circ}$. Valla. Es todo anuncio permanente o temporal utilizado como medio masivo de comunicación, que permite difundir mensajes publicitarios, cívicos, comerciales, turísticos, culturales, políticos, institucionales, artísticos,

Ley 140 de 1994 informativos o similares;

que se coloca para su apreciación visual en lugares exteriores y que se encuentra montado sobre una estructura metálica u otro material estable con sistemas fijos; el cual se integra física, visual, arquitectónica y estructuralmente al elemento que lo soporta [...].
Valla que no cumple técnicamente con las medidas de construcción, y ubicada al lado de vía principal.

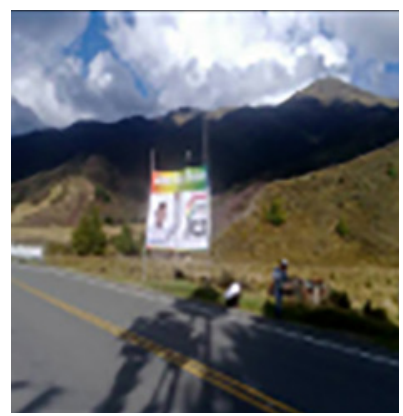

Código Civil

(Artículo XX), Código Electoral (Artículo 29) y Código de Tránsito (Artículo XX) 
Artículo $4^{\circ}$. Condiciones de la Publicidad Exterior Visual en zonas urbanas y rurales. La Publicidad Exterior Visual que se coloque en las áreas urbanas de los municipios, distritos Ley $140 \quad$ y también en los territorios de 1994 indígenas, deberá reunir los (junio 23) siguientes requerimientos:

a) Distancia: Podrán colocarse hasta dos vallas contiguas con la Publicidad Exterior Visual. La distancia mínima con las más próximas no puede ser inferior a 80 metros [...].
Vallas de candidatos al Congreso, cerca de vía principal, zona rural municipio de Sogamoso.

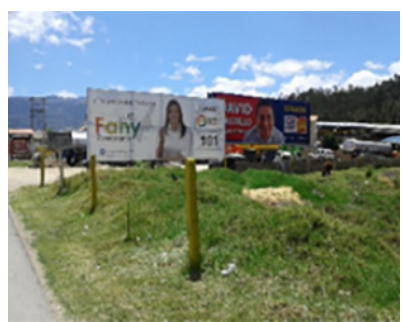

Código Electoral

(Artículo 29)

y Código de Tránsito

(Artículo XX)
Artículo $2^{\circ}$. Definiciones.

Para la aplicación e interpretación de este código, se tendrán en

Ley 769

de 2002

(6 de julio)

cuenta las siguientes

definiciones:

Vehículo agrícola:

Vehículo automotor provisto de una configuración especial, destinado exclusivamente a labores agrícolas

\section{Empleo de} maquinaria agrícola especializada para promocionar correría de campaña de aspirante a la Cámara, sin medidas de seguridad.

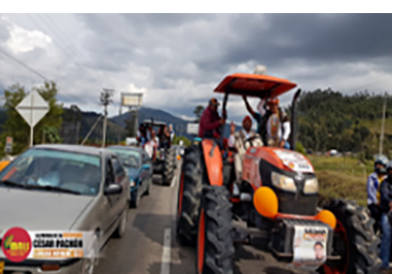

Código de Tránsito

(Artículo XX)
Artículo 83. Prohibición de llevar pasajeros en la parte exterior del vehículo. Ningún vehículo podrá llevar pasajeros en su parte exterior, o fuera de la

Ley 769

de 2002 (6 de julio) cabina, salvo aquellos que por su naturaleza así lo requieran, tales como los vehículos de atención de incendios y recolección de basuras. No se permite la movilización de pasajeros en los estribos de los vehículos.
Caravana de seguidores de candidato al Congreso, empleando vehículo con pasajeros de pie.

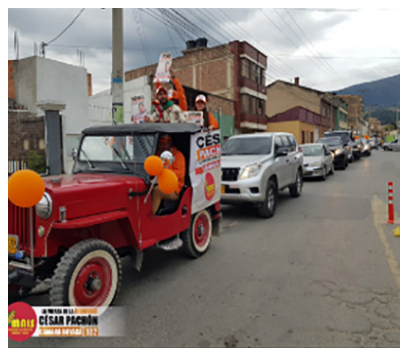

Código Naciona de Tránsito (Capítulo III Conducción de vehículos)

\section{Artículo 94. Normas} generales para bicicletas, triciclos, motocicletas, motociclos y mototriciclos. Los conductores de estos tipos de vehículos y sus acompañantes deben vestir chalecos o chaquetas reflectivas de identificación que deben ser visibles

Ley 769

de 2002

(6 de julio) cuando se conduzca entre las 18:00 y las 6:00 horas del día siguiente, y siempre que la visibilidad sea escasa. Los conductores y los acompañantes cuando hubieren, deberán utilizar casco de seguridad, de acuerdo como fije el Ministerio de Transporte. La no utilización del casco de seguridad cuando corresponda dará lugar a la inmovilización del vehículo.

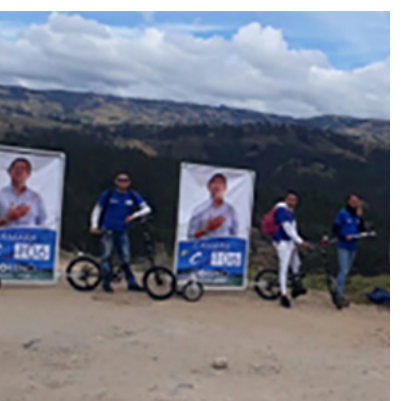

Código Nacional de Tránsito promocionando la Cámara de Representantes, sin medidas de seguridad
(Capítulo V Ciclistas y motociclistas)

Fuente: Elaboración propia por parte de los autores 
en la actualidad no existe en el orbe campaña electoral que prescinda, de uno $\mathrm{u}$ otro modo, del acompañamiento musical (Valdez, Huerta, Aguilar, 2011)

Lo anterior terminó siendo común en las campañas para Congreso 2018 en Boyacá: la utilización de diversos medios sonoros los casos del perifoneo móvil, ambientación musical en lugares públicos y privados, alocución política, lanzamiento de voladores pirotécnicos, bocinas de automóviles y efectos de sonidos como sirenas (ambulancia) que sirvieron de estrategias 'sonoras persuasivas' en los intereses electivos de los aspirantes a la Cámara de Representantes o Senado.

En lo pertinente a la persuasión electoral, Mc-Guire (1981), citada por Crespo (2011), menciona algunas categorías efectivas en campañas política: estimulación, teleología, afirmación, identificación, empatía, contagio, repetición, entre otras. El presente estudio se ubica en las dos últimas categorías, debido a la manera más específica o relación directa que existe con el caso:

Contagio: esta categoría es conocida con variados nombres, como facilitación, imitación, modelización, aprendizaje social, etcétera. Se enfoca en la idea de que la gente imita a otros que observan, adoptando automáticamente pensamientos, formas o sentimientos, y jugando con las creencias de esos modelos.

Repetición: sostienequela tendencia delas personas basada en actos o performances anteriores es actuar repetidamente en determinadas instancias, particularmente frente a situaciones presentes de alta similitud o familiaridad. (Crespo, et. all., 2011, pp.137-139)

Es decir, las anteriores categorías son relacionadas al estudio, desde los 'contagios' sonoros y rítmicos en el ambiente público que generaron las campañas de los aspirantes al Congreso 2018 en Boyacá, lo que llevó a provocar contravenciones que "afectaron la tranquilidad y relaciones respetuosas de las personas" (Artículo 33 - Código Nacional de Policía); en tanto los mensajes públicos emitidos de forma 'repetitiva' fueron notorios mediante el perifoneo permanente, las alocuciones en plaza, y los habituales discursos orales en espacios abiertos y cerrados, válidos en los procesos electorales efectuados en las sociedades modernas donde se garantiza la participación democrática, pero termina generando malestar en las comunidades cuando los espacios deliberativos existen confrontación o aglomeraciones que perturban directamente el equilibrio público.

\section{Discusión legal y teórica}

A pesar del Decreto 0384 de diciembre 31/2017 emitido por la alcaldía de Tunja, el cual se soporta en las facultades constitucionales otorgadas en la Ley 130 de 1994, donde el artículo 29 'Propaganda en espacios públicos' señala:

Corresponde a los Alcaldes y los Registradores Municipales regular la forma, característica, lugares y condiciones para la fijación de carteles, pasacalles, afiches y vallas destinadas a difundir propaganda electoral, a fin de garantizar el acceso equitativo de los partidos y movimientos, agrupaciones y candidatos a la utilización de estos medios, en armonía con el derecho de la comunidad a disfrutar del uso del espacio público y a la preservación de la estética. También podrán, con los mismos fines, limitar el número de vallas, afiches y elementos publicitarios destinados a difundir propaganda electoral. (Ley 130, 1994)

Las faltas electorales fueron evidentes, como se demostró en las anteriores líneas. Esto fue el producto de las correrías tradicionales de hacer proselitismo político en Colombia, donde persiste la utilización de medios artesanales, por ejemplo empapelar con publicidad política los muros o fachadas del inmobiliario público $\mathrm{y}$ privado, desfiles de automotores en vías urbanas y rurales, concentración en espacios públicos con animación de grupos musicales, expendio y consumo de licor sin ningún control gubernamental, utilización de medios publicitarios improvisados (triciclo publicitario, fijación de pasacalles en lugares prohibidos, avisos publicitarios no fijos). Todos estos hacen parte de la numerosa lista de métodos empleados por los candidatos para promover la campaña, que terminan generando contravenciones electorales, y lógicamente esto atenta contra la transparencia del mismo.

Esto puede catalogarse como muestra de la cultura politica local desde la puesta en marcha de elecciones populares, donde aún existen en el departamento de Boyacá 'viejas formas de hacer campaña política', como desarrollar estrategias de "pintar bardas, hacer mítines y participar en 
caravanas" (Freidenberg \& González, 2009, p. 270), algo común en una región donde predomina el dominio de partidos políticos tradicionales y el desarrollo de usuales estrategias de proselitismo electoral en los propios candidatos. Lo anterior, ligado a la cultura política, determinada como "el resultado de la historia del sistema político y de los miembros de ese sistema" según Robert Dowse (1977). De otra parte, Luis Morfin (1994) citado por Garcés, Palacio y Aguilar (2010) define la cultura política desde una mirada axiológica, apuntando al conjunto de significados y de valores que al ser apropiados e interiorizados por grupos humanos influyen en la toma decisiones y constituyen la razón de ser de la comunidad política.

Es decir, el primer esbozo conceptual deduce el comportamiento de las comunidades boyacenses en los procesos electorales, este resulta sujeto a la identidad propia que representa el sistema político local, lo cual genera conductas afines [Historia S.P./Miembros S.P.]. El segundo término lleva a concluir los valores expuestos por parte de los miembros que intervienen en las votaciones populares, terminan generando de forma irracional conductas delictivas que atentan contra el aparato jurídico en materia de derecho electoral, los casos de ejercer un proselitismo político mediante el empleo de estrategias: fiestas carnavalescas electoral con las comunidades, que representan show de grupos musicales, consumo de bebidas alcohólicas sin ningún control, entrega de obsequios (electrodomésticos, alimentos, material de construcción, etcétera), forman parte de una cultura electoral asistencialista que aprovechan las campañas electorales para beneficiarse de dichas dádivas políticas.

En ese sentido, José María Baviano (1977), en su artículo 'Fiestas electorales, un sistema eficaz de captación de votos' sostiene que "La mayoría de los partidos que concurren a batallas electorales para el Congreso y el Senado, han intentado demostrar su poder de captación de masas en mítines, conferencias y presentaciones. Sin embargo, algunos partidos han demostrado a lo largo de esta campaña tener un mayor poder de convocatoria, han dejado como momentos importantes los de celebración de fiestas electorales”. Estas suelen caracterizarse por el compartir de "elementos típicos de una fiesta popular, gigantes y cabezudos, guiñol, fotos trucadas y puestos de refrescos y bocadillos" (Baviano, 1977). Para el caso boyacense, las fiestas electorales terminan siendo acompañadas por el acompañar de platos típicos de la región, consumo gratis de bebidas alcohólicas, entrega de premios, y presentación de artistas populares.

Tales expresiones político-culturales, también recibe el nombre de "performance político-cultural que es el mitin, es el proceso social en el cual los actores muestran a otros el significado de ciertas relaciones sociales políticas" (Ortiz Marín, 2014, p. 3). Igualmente, el autor destaca que

el mitin es una forma de manifestación pública que resulta esencial para comprender el tiempo de la política. Ante todo, porque los mítines señalan... la ruptura con la cotidianeidad. El mitin se asemeja a la celebración de una fiesta. Hay un proceso de preparación, cuyo tiempo varía según la importancia del mismo, tanto los asistentes como los convocantes se preparan para la misma, ya sea en el avituallamiento, la escenografía, la música, incluso un presentador (si es el caso) y por supuesto, la vestimenta y en algunas reuniones, la preparación de los alimentos y bebidas. (2014, p. 14)

Prácticas electorales comunes, empleadas especialmente en el cierre de campaña, donde los candidatos aprovechan la ocasión para lograr la catación de votos mediante la utilización de métodos populistas a favor de sus intereses electorales. Por ello es necesario ejercer en un solo escenario shows musicales, de partición de licores y la entrega de premios como estrategias de persuasión política que garanticen un posible escaño en cualquier cargo de representación gubernamental. Bajo esta fórmula de comunicación política, el proceso electoral termina convirtiéndose en un debate contravencional que afecta el propio sistema electoral colombiano.

\section{Conclusiones}

Retomando la pregunta principal: ¿Cuál fue el comportamiento de los candidatos de Boyacá al Congreso de la República 2018, frente a las contravenciones electorales en materia de publicidad política?, y señalando las sub-preguntas: P1-¿Cómo se manifestó la contravención electoral en las actuaciones de candidatos al Congreso 2018 en el departamento de Boyacá?; P2-¿De qué manera se muestran las faltas más comunes en materia de publicidad política que cometieron los candidatos al Legislativo por Boyacá-2018?; y P3¿Qué acciones llevó a cabo la Alcaldía de Tunja para evitar una posible omisión de las normas 
electorales, en lo pertinente a la publicidad política exterior?, logramos relacionar en su orden algunas consideraciones finales que evidencian destacados hallazgos en las afirmaciones expuestas.

Con relación a la pregunta $\mathrm{P} 1$, existe probablemente desconocimiento u omisión del Código Electoral colombiano en la mayoría de candidatos que intervinieron en los comicios Congreso 2018 en Boyacá, especialmente en la utilización o manejo dado a la publicidad y propaganda política en espacios públicos, donde fue notorio diversas formas de violar los artículos estipulados. Asimismo, los propios partidos y movimientos políticos asumieron una conducta flemática ante las reiterativas contravenciones al Código especializado. Por su parte, los órganos gubernamentales encargados de garantizar la transparencia de los procesos electorales en Colombia, como el Consejo Nacional Electoral y la Registraduría Nacional del Estado Civil, también actuaron de manera indiferente ante las faltas de los aspirantes y los grupos políticos.

De igual forma, fue notable el aprovechamiento de la infraestructura física del Estado para proyectar la publicidad política en postes de redes eléctricas, puentes peatonales y muros de contención, generándose algunas faltas, especialmente al detrimento público del Estado; precisamente la Ley 610 de 2000 en el artículo 6 establece este daño consiste fundamentalmente en una lesión del patrimonio público, representada en el menoscabo, disminución, perjuicio, detrimento, pérdida o deterioro de los bienes o recursos públicos o de los intereses patrimoniales del Estado, por una mala gestión fiscal, fenómeno que sucede en el caso del pago de multas, sanciones e intereses de mora, de una entidad pública a otra.

En tanto las violaciones más comunes en materia de publicidad política hallados en la pregunta P2, estuvieron presentes en infracciones a los códigos Civil, Electoral, Tránsito y Transporte, y Nacional de Policía. Sustancialmente en el artículo XX del Código Civil, el 29 del Código Electoral, los capítulos III y V del Código Nacional de Tránsito, y contravenciones en los artículos 29 y 47 del Código Nacional de Policía. Estos representados en las leyes 140 de 1994 (junio 23), 769 de 2002 (6 de julio), y 1801 de 2016.

Por último, la afirmación P3 resalta las acciones de la Alcaldía de Tunja, con la fijación del Decreto 0384 de diciembre 31/2017, donde reglamenta la propaganda electoral en espacios públicos; sin embargo, tal norma fue insignificante ante los deseos de los candidatos a la Cámara y Senado, quienes se valieron de cualquier medios físico para promover sus propuestas, desconociendo en la mayoría de casos no solamente el aparato jurídico colombiano, sino también los riesgos para la salud pública que genera la ubicación errada de cualquier elemento publicitario; de igual forma, el aprovechamiento del espacio público junto con la preservación de la estética, y el detrimento patrimonial que ocasiona el mal uso de la infraestructura gubernamental.

\section{Referencias}

Alcaldía Mayor de Tunja. (31 de diciembre de 2017). Decreto Por el cual se adoptan normas reglamentarias sobre publicidad politica electoral. [0384 de 31 diciembre 2017]. Do: Alcaldía de Tunja.

Baviano, J. (11 de junio de 1977). Fiestas electorales, un sistema eficaz de captación de votos. El País. Recuperado de https://elpais.com/diario/1977/06/11/ espana/234828012_850215.html

Congreso de Colombia. (23 de junio de 1994). Ley Por el cual se reglamenta la Publicidad exterior Visual en el territorio nacional. [140 de 1994]. Do: Diario Oficial, Santafé de Bogotá.

Congreso de Colombia. (31 de julio de 2007). Ley por medio de la cual se establece el tratamiento de las pequeñas causas en materia penal. [1153 de 2007]. Do: Diário Oficial, Bogotá.

Congreso de Colombia. (29 de julio de 2016). Por la cual se expide el Código Nacional de Policía y Convivencia. [1801 de 2016]. Do: Diario Oficial, Bogotá

Crespo, I., Garrido, A., Carletta, I., \& Riorda, M. (2011). Manual de comunicación política y de campaña. Buenos Aires: Biblos.

Diccionario del español jurídico [DEJ]. (2018). Contravención. Recuperado de http://dej.rae.es/\#/entry-id/ $\underline{\mathrm{E} 152500}$

Duarte Murillo, D. (2012). Código de Tránsito Terrestre. Bogotá: Editorial LEYER.

Duarte Murillo, D. (2015). Código de Tránsito y Transporte. Bogotá: Editorial LEYER.

Enciclopedia jurídica. (2014). Contravención. Recuperado

de http://www.enciclopedia-juridica.biz14.com/d/contravenci\%C3\%B3n/contravenci\%C3\%B3n.htm

Freidenberg, F. \& González, L. (2009). Estrategias partidistas, preferencias ciudadanas y anuncios televisivos. Un análisis de la campaña electoral mexicana de 2006. Política y gobierno (volumen XVI, número 2), pp. 269-320.

Garcés, P., Miguel E., Palacio, J. \& Aguilar, D. (2010). Análisis de la cultura política de Montería en el periodo 2006-2008, desde las categorías de 
participación y comunicación política. Investigación y desarrollo, (vol. 18 número 1), pp. 4467.

González Andrade, Fabricio. (2006). Ensayos médicos sobre genética. Lagenética molecular en la medicina ecuatoriana. Imprenta Noción: Quito-Ecuador.

Ministerio de Justicia y del Derecho [MINJUSTICIA]. (sf.). ABC LegalApp. Recuperado de https://www.legalapp.gov.co/abc-legalapp

Misión de Observación Electoral-MOE. (2015). La propaganda política en las campañas electorales en Colombia. Bogotá: MOE, Recuperado de https:// moe.org.co/home/doc/moe_juridica/2015/La_propaganda_politica_en_colombia.pdf

Ortiz Marín, A. (27 de agosto de 2014). La fiesta de la política. Las campañas electorales del 2013 en Baja California, México. IV Encuentro Latinoamericano de Metodología de las Ciencias Sociales. Facultad de Humanidades y Ciencias de la educación - Universidad Nacional de La Plata. Recuperado de http://www.memoria.fahce. unlp.edu.ar/trab_eventos/ev.8318/ev.8318.pdf

Ossorio, M. (1981). Diccionario de ciencias jurídicas, políticas y sociales. Buenos Aires-Argentina: Editorial Heliasta S.R.L., págs. 797.

Real Academia Española. Diccionario de la lengua española. (Edición del Tricentenario).

Román Rodríguez, M. E. (2015). Delitos menores cometidos en grandes superficies, problemas y alternativas planteadas por el legislador. Revista Pensamiento penal (octubre 15 de 2015), 1-38, Recuperado de http://www.pensamientopenal.com. ar/system/files/2015/10/doctrina42186.pdf

Sierra Bravo, R. (1998). Técnicas de investigación social. Teoría y ejercicios. España: Paraninfo.

Torres Rico, R. (2008). Delitos y contravenciones como factores de criminalidad y de perturbación de la convivencia social. Revista Criminalidad Policía Nacional-DIJIN, 50(1), 85-98 páginas, Recuperado de http://www.scielo.org.co/pdf/crim/v50n1/ v50n1a06.pdf

Valdez, A., Huerta, D. \& Aguilar, A. (2011). La música en las campañas y su efecto en la conducta de los electorales. El caso de la campaña presidencial de Barack Obama. Revista Enfoques, No 15, 53-73 páginas, Recuperado de https://www. redalyc.org/html/960/96021303004/ 